\title{
A case-control study of smoking and sudden infant death syndrome in the Scandinavian countries, 1992 to 1995
}

\begin{abstract}
B Alm, J Milerad, G Wennergren, R Skjærven, N Øyen, G Norvenius, A-K Daltveit, K Helweg-Larsen, T Markestad, L M Irgens, on behalf of the Nordic Epidemiological SIDS Study
\end{abstract}

Department of Paediatrics, Sahlgrenska University Hospital/Östra, Göteborg, Sweden B Alm

G Wennergren

$G$ Norvenius

Department of Paediatrics, Karolinska Hospital, Stockholm, Sweden J Milerad

Department of Public Health and Primary Health Care, University of Bergen and Medical Birth

Registry of Norway, Bergen, Norway R Skjærven

$\mathrm{N}$ Øyen

A-K Daltveit

L M Irgens

Danish Institute for Clinical Epidemiology, Copenhagen, Denmark K Helweg-Larsen

Department of Paediatrics, University of Bergen, Norway T Markestad

Correspondence to: Dr B Alm, Department of Paediatrics, Sahlgrenska University Hospital/Östra, S-416 85 Göteborg, Sweden.

Accepted 10 November 1997

\begin{abstract}
Aim-To establish whether smoking is an independent risk factor for sudden infant death syndrome (SIDS), if the effect is mainly due to prenatal or postnatal smoking, and the effect of smoking cessation. Methods-The analyses were based on data from the Nordic epidemiological SIDS study, a case-control study with 244 cases and 869 controls. Odds ratios were computed by conditional logistic regression analysis.

Results-Smoking emerged as an independent risk factor for SIDS, and the effect was mainly mediated through maternal smoking in pregnancy (crude odds ratio 4.0 (95\% confidence interval 2.9 to 5.6)). Maternal smoking showed a marked dose-response relation. There was no effect of paternal smoking if the mother did not smoke. Stopping or even reducing smoking was beneficial. SIDS cases exposed to tobacco smoke were breast fed for a shorter time than non-exposed cases, and feeding difficulties were also more common.

Conclusions-Smoking is an independent risk factor for SIDS and is mainly mediated through maternal smoking during pregnancy. Stopping smoking or smoking less may be beneficial in reducing the risk of SIDS.
\end{abstract}

(Arch Dis Child 1998;78:329-334)

Keywords: sudden infant death; smoking; epidemiology; pregnancy

Smoking in pregnancy was first associated with sudden infant death syndrome (SIDS) in 1966. ${ }^{1}$ In the Nordic countries, this was observed by Rintahaka, ${ }^{2}$ who attributed the increased risk of SIDS associated with smoking to fetal hypoxaemia during pregnancy. In subsequent studies, it has been a general finding that smoking increases the risk of cot death. ${ }^{34}$ Moreover, it is not fully established whether the risk is highest for smoking during ${ }^{12}$ or after pregnancy, ${ }^{5-11}$ to what extent smoking by the father and other members of the household adds to the risk, ${ }^{9-12}$ and whether there are interactions with other risk factors. Thus there is still controversy on how smoking exerts its effects and whether smoking is a confounder for social factors.
The aims of this study were to determine whether smoking is an independent risk factor for SIDS, whether the effect is mainly due to maternal smoking during pregnancy or to passive smoking, and if there is an effect of smoking cessation. Furthermore, we wanted to assess whether the effects on SIDS of other prenatal and postnatal risk factors are different in children of smoking and non-smoking mothers. Finally, we investigated the effects of the different smoking habits in the Scandinavian countries.

\section{Methods}

Between 1 September 1992 and 31 August 1995, parents of 294 cases of SIDS in the Scandinavian countries were invited by the local paediatrician (Norway and Sweden) or forensic institute (Denmark) to participate in the study. Of these, 244 families (83\%) accepted. For each case, six controls matched for sex, date of birth plus two weeks, and maternity hospital were selected. The delay period of two weeks was allowed in order to obtain a similar age for the controls and the SIDS victims when the questionnaire was completed. The first four were invited to participate in the study. If a family was reluctant to enter the study, one of the two remaining controls was invited. Of 1207 invited control families, 869 (72\%) participated.

The cases and controls were sent a questionnaire consisting of 272 questions. The questions analysed here concern maternal and paternal smoking before, during, and after pregnancy. Cigarette doses during pregnancy were recorded for the first and the third trimester separately. The number of persons smoking in the household was reported, as well as the number of cigarettes smoked. Birth weight, age at death/interview, age at weaning, prematurity, and perinatal problems were included in the analysis, as were use of dummies, incidence of infections, use of antibiotics, and hospital admission after the perinatal period. Basic medical and social data concerning the family were also analysed. Unfortunately control questionnaires took longer to complete than anticipated, which resulted in an age difference between cases and controls: cases, 16.1 weeks, $95 \%$ confidence interval 14.7 to 17.5 ; controls, 21.4 weeks, 20.5 to 21.8 .

Necropsy was performed in every case. In Denmark and Sweden, $98 \%$ of the necropsies were performed at departments of forensic 
Table 1 Parental and other household smoking in SIDS cases and controls with crude and adjusted odds ratios (OR) in Scandinavia 1992 to 1995, the Nordic epidemiological SIDS study

\begin{tabular}{|c|c|c|c|c|c|c|c|c|c|c|c|c|c|}
\hline \multirow[b]{2}{*}{ Household smoking } & \multicolumn{2}{|c|}{ Cases } & \multicolumn{2}{|c|}{ Controls } & \multicolumn{3}{|c|}{ Crude } & \multicolumn{3}{|c|}{ Adjusted for age } & \multicolumn{3}{|c|}{$\begin{array}{l}\text { Adjusted for age, maternal age, } \\
\text { and education }\end{array}$} \\
\hline & No & $\%$ & No & $\%$ & $O R$ & $95 \% C I$ & $p$ & $O R$ & $95 \% C I$ & $p$ & $O R$ & $95 \% C I$ & $p$ \\
\hline \multicolumn{14}{|l|}{ Maternal smoking } \\
\hline Before pregnancy & 151 & 68.3 & 336 & 41.4 & 3.0 & 2.2 to 4.1 & $<0.001$ & 3.2 & 2.2 to 4.7 & $<0.001$ & 2.5 & 1.7 to 3.7 & $<0.001$ \\
\hline During pregnancy & 150 & 61.7 & 253 & 29.4 & 4.0 & 2.9 to 5.6 & $<0.001$ & 4.5 & 3.1 to 6.6 & $<0.001$ & 3.6 & 2.4 to 5.3 & $<0.001$ \\
\hline After pregnancy & 146 & 60.1 & 263 & 30.7 & 3.8 & 2.8 to 5.3 & $<0.001$ & 4.5 & 3.1 to 6.6 & $<0.001$ & 3.7 & 2.5 to 5.5 & $<0.001$ \\
\hline \multicolumn{14}{|l|}{ Paternal smoking } \\
\hline Before pregnancy & 114 & 51.6 & 322 & 40.0 & 1.6 & 1.2 to 2.1 & 0.005 & 1.7 & 1.2 to 2.5 & 0.003 & 0.8 & 0.5 to 1.2 & 0.26 \\
\hline During pregnancy & 119 & 50.6 & 319 & 37.3 & 1.7 & 1.3 to 2.3 & $<0.001$ & 1.8 & 1.2 to 2.5 & 0.002 & 0.9 & 0.6 to 1.4 & 0.62 \\
\hline After pregnancy & 117 & 50.2 & 284 & 33.2 & 2.0 & 1.5 to 2.8 & $<0.001$ & 2.3 & 1.6 to 3.3 & $<0.001$ & 1.2 & 0.8 to 1.9 & 0.30 \\
\hline \multicolumn{14}{|l|}{ Other smoking } \\
\hline After pregnancy & 33 & 14.0 & 73 & 8.4 & 2.0 & 1.3 to 3.3 & 0.004 & 2.1 & 1.2 to 3.6 & 0.007 & 1.2 & 0.6 to 2.2 & 0.57 \\
\hline
\end{tabular}

* Paternal and other smoking also adjusted for maternal smoking in pregnancy; $\mathrm{CI}=$ confidence interval.

medicine. The SIDS diagnosis was verified according to criteria of the pathology group of the Nordic SIDS study. ${ }^{13}$ In Norway, necropsies were also performed at hospital pathology departments for geographical reasons, but according to the same protocol. ${ }^{13}$ All necropsies can thus be regarded as having the same high validity. The material has been described in more detail by Øyen et al. ${ }^{14}$

Odds ratios (OR) were calculated by conditional logistic regression ${ }^{15}$ using the SPSS statistical software package. ${ }^{16}$ The attributable fraction (AF) was calculated for the whole material and for the participating countries from the data in tables 1 and 6 from the formula: $\mathrm{AF}=$ per cent exposed cases $\times$ $((\mathrm{OR}-1) / \mathrm{OR}){ }^{17}$ Additive interactions were tested by the EGRET statistical package,${ }^{18}$ and multiplicative interactions by conditional logistic regression. ${ }^{15}$

\section{Results}

ODDS RATIO AND DOSE-RESPONSE RELATION Crude odds ratios (95\% confidence intervals) for maternal smoking before, during, and after pregnancy were 3.0 (2.2 to 4.1 ), 4.0 (2.9 to 5.6), and 3.8 (2.8 to 5.3) respectively (table 1 ). Odds ratios for paternal smoking were $1.6(1.2$ to 2.1 ), 1.7 (1.3 to 2.3 ), and 2.0 (1.5 to 2.8 ), and for other household members smoking postnatally 2.0 (1.3 to 3.3 ). Odds ratios were adjusted for age of infant as well as age and educational level of mother. Additional adjusting for birth weight reduced the effects marginally. Paternal smoking and other smoking were adjusted for maternal smoking in pregnancy. After adjustment, there was no effect of paternal smoking or other smoking (table 1). This was confirmed in a stratified analysis in which there was no effect of paternal smoking if the mother did not smoke (table 2).

Table 2 Combinations of maternal smoking in pregnancy and paternal smoking after pregnancy in SIDS cases and controls with crude odds ratios (OR) in Scandinavia 1992 to 1995, the Nordic epidemiological SIDS study

\begin{tabular}{|c|c|c|c|c|c|c|c|c|}
\hline \multirow{2}{*}{$\begin{array}{l}\text { Mother smoked } \\
\text { in pregnancy }\end{array}$} & \multirow{2}{*}{$\begin{array}{l}\text { Father smoked } \\
\text { after pregnancy }\end{array}$} & \multicolumn{2}{|c|}{ Cases } & \multicolumn{2}{|c|}{ Controls } & \multirow[b]{2}{*}{$O R$} & \multirow[b]{2}{*}{$95 \% C I$} & \multirow[b]{2}{*}{$p$} \\
\hline & & No & $\%$ & No & $\%$ & & & \\
\hline No & No & 74 & 31.8 & 462 & 54.4 & 1.0 & Reference & \\
\hline No & Yes & 18 & 7.7 & 138 & 16.3 & 0.8 & 0.5 to 1.5 & 0.56 \\
\hline Yes & No & 42 & 18.0 & 108 & 12.7 & 2.6 & 1.7 to 4.0 & $<0.001$ \\
\hline Yes & Yes & 99 & 42.5 & 141 & 16.6 & 4.4 & 3.0 to 6.5 & $<0.001$ \\
\hline
\end{tabular}

$\mathrm{CI}=$ confidence interval
To evaluate dose-response relations, crude odds ratios for both maternal and paternal smoking before, in the first trimester, in the third trimester, and after pregnancy were calculated in different dose strata (nil, 1-9, 10-19, and $>20$ cigarettes/day). We found an obvious dose-response relation for maternal smoking (fig 1).

\section{SMOKING CESSATION}

To assess possible effects of maternal smoking cessation, mothers who stopped smoking were divided into three groups. First, those who smoked before pregnancy but stopped permanently when they realised that they were pregnant (early cessation); second, those who stopped when the baby was born (late cessation); and third, those who smoked before pregnancy, stopped during it, but resumed smoking postpartum (partial cessation, table $3)$. Relatively few mothers changed their smoking behaviour (23 of 151 cases (15\%) and 150 of 334 controls (45\%)), but in neither group did we find any significant risk increase compared with mothers who never smoked. The odds ratio for early cessation was $0.7(0.3$ to 1.4 ), late cessation 1.1 (0.5 to 2.4$)$, and partial cessation $1.1(0.4$ to 3.2 ) (table 3$)$. The mothers who continued to smoke throughout pregnancy and thereafter had an odds ratio of 4.5 (3.1 to 6.5 ).

To determine why late cessation was not associated with an increased risk, even though the mothers of these infants had smoked during pregnancy, we compared the number of cigarettes consumed by the late ceasers and the non-ceasers. We found that the late ceasers smoked less than the non-ceasers during pregnancy, both in the first and the third trimester. In the first trimester, late ceasers consumed 5.1 cigarettes/day ( $95 \%$ confidence interval 2.1 to 8.2) against 9.3 cigarettes/day (8.7 to 9.9) for non-ceasers. The numbers in the third trimester were 5.3 (2.9 to 7.6 ) and 8.3 (7.7 to 8.9) respectively. We also tried to adjust for the amount smoked, but the results did not clarify the issue.

PERINATAL AND POSTNATAL PROBLEMS The differences between SIDS cases and controls exposed and not exposed to maternal smoking in utero and postnatally are shown in tables 4 and 5 . The variables initially investigated were: age, birth weight, age at weaning, 


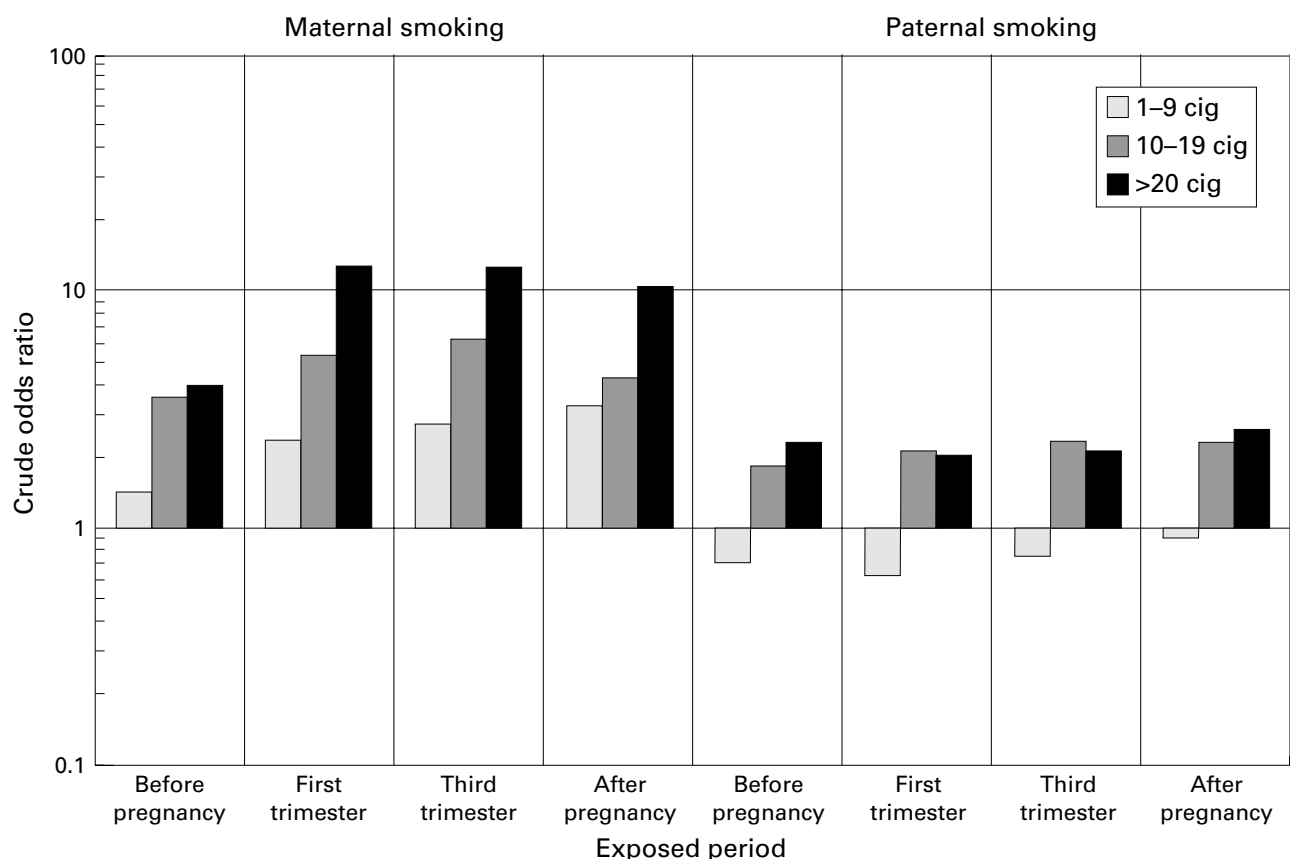

Figure 1 Crude odds ratios (log scale) for maternal and paternal smoking doses in different dose strata by exposed period in Scandinavia 1992 to 1995 (the Nordic epidemiological SIDS study); cig = cigarettes.

prematurity, induction of labour, vacuum extraction, caesarean section, resuscitation, admission to neonatal ward, problems during the first week (floppiness, irritability, weak sucking, and vomiting), problems after the first week (floppiness, activity, and irritability), feeding habits, infantile colic, symptoms of infection, antibiotic treatment, admission to hospital after discharge from maternity ward, use of a dummy (pacifier), regurgitation/ vomiting, and depth of sleep as estimated by the parents. We chose variables which had effects that might be modified by maternal smoking. Of these variables, only the ones given in tables 4 and 5 showed significant differences. There was no age difference between the groups in this study: mean age at death was 16.1 weeks in the non-exposed group and 15.9 in the exposed group ( $\mathrm{p}=$

Table 3 Crude odds ratios (OR) for SIDS by maternal smoking career in Scandinavia 1992 to 1995, the Nordic epidemiological SIDS study

\begin{tabular}{|c|c|c|c|c|c|c|c|}
\hline \multirow{2}{*}{$\begin{array}{l}\text { Maternal smoking } \\
\text { career }\end{array}$} & \multicolumn{2}{|c|}{ Cases } & \multicolumn{2}{|c|}{ Controls } & \multirow[b]{2}{*}{$O R$} & \multirow[b]{2}{*}{$95 \% C I$} & \multirow[b]{2}{*}{$p$} \\
\hline & No & $\%$ & No & $\%$ & & & \\
\hline Never smoked & 67 & 30.7 & 430 & 56.3 & 1.0 & Reference & - \\
\hline Early cessation ${ }^{\star}$ & 9 & 4.1 & 68 & 8.9 & 0.7 & 0.3 to 1.4 & 0.30 \\
\hline Late cessation $\nmid$ & 10 & 4.6 & 54 & 7.1 & 1.1 & 0.5 to 2.4 & 0.73 \\
\hline Partial cessation $\ddagger$ & 4 & 1.8 & 28 & 3.7 & 1.1 & 0.4 to 3.2 & 0.92 \\
\hline Non-cessation & 128 & 58.7 & 184 & 24.1 & 4.5 & 3.1 to 6.5 & $<0.001$ \\
\hline
\end{tabular}

^Stopped smoking when they became pregnant.

†Stopped smoking postpartum.

$\ddagger$ Stopped during pregnancy but resumed smoking postpartum

Table 4 Age, birth weight, and weaning of SIDS cases and controls exposed to prenatal maternal smoking compared with non-exposed cases and controls in Scandinavia 1992 to 1995, the Nordic epidemiological SIDS study

\begin{tabular}{|c|c|c|c|c|c|c|}
\hline \multirow[b]{2}{*}{ Characteristics } & \multicolumn{3}{|l|}{ SIDS cases } & \multicolumn{3}{|l|}{ SIDS controls } \\
\hline & Non-exposed & Exposed & $p$ & Non-exposed & Exposed & $p$ \\
\hline Age (weeks; 95\% CI) & 16.1 (13.8 to 18.4$)$ & 15.9 (14.2 to 17.6$)$ & 0.90 & 21.2 (20.2 to 22.3$)$ & 21.9 (20.3 to 23.5$)$ & 0.50 \\
\hline Birth weight (g; 95\% CI) & 3340 (3161 to 3517 ) & 3065 (2950 to 3178$)$ & 0.007 & 3653 (3610 to 3696$)$ & $3462(3399$ to 3525$)$ & $<0.001$ \\
\hline Weaning (weeks; $95 \%$ CI) & 11.9 (8.1 to 15.6$)$ & $8.0 \quad(6.4$ to 9.7$)$ & 0.036 & $15.4(13.7$ to 17.1$)$ & 11.7 (9.8 to 13.6$)$ & 0.004 \\
\hline
\end{tabular}

0.90). Cases had lower birth weight than controls, regardless of exposure, and smoke exposed infants had lower birth weight than non-exposed infants. Exposed cases stopped breast feeding earlier ( 8.0 weeks $v 11.9$ weeks, $\mathrm{p}=0.036$ ) (table 4).

Among the controls, infants of smoking mothers more often had problems related to breast feeding $(49.2 \% \vee 29.9 \%)$, as well as infections $(51.8 \% \vee 48.8 \%)$, and were more often admitted to hospital $(24.2 \% v 19.0 \%)$ and treated with antibiotics $(24.2 \% v 17.1 \%)$ (table 5). The only exception was poor sucking, which was more prevalent among infants of non-smoking mothers. The effect of poor sucking was much stronger in infants of smoking mothers $(\mathrm{p}=0.01$ in a multiplicative model). The same tendency (not significant) was observed for breast feeding. Otherwise, there was a tendency (not significant) towards smaller effects among infants of smoking mothers. We assessed possible effect modifications of smoking on the following variables: low birth weight, low maternal education, prone sleeping position, high parity, and low maternal age. No significant interactions were observed, except for an additive interaction with position placed to sleep the last time $(\mathrm{p}<0.001)$, which is described elsewhere. ${ }^{14}$ 
Table 5 Interaction between prenatal smoking and perinatal and postnatal characteristics of SIDS cases and controls in Scandinavia 1992 to 1995 , the Nordic epidemiological SIDS study

\begin{tabular}{|c|c|c|c|c|c|c|c|c|c|c|}
\hline & & \multicolumn{2}{|c|}{ Cases } & \multicolumn{2}{|c|}{ Controls } & \multirow[b]{2}{*}{$O R$} & \multirow[b]{2}{*}{$95 \% C I$} & \multirow[b]{2}{*}{$p$} & \multicolumn{2}{|c|}{ Test for interaction $(p)$} \\
\hline & & No & $\%$ & $\mathrm{No}$ & $\%$ & & & & Additive & Multiplicative \\
\hline Prenatal smoking & Poor sucking & & & & & & & & & \\
\hline No & No & 86 & 94.5 & 545 & 90.7 & 1.0 & Reference & - & 0.07 & 0.010 \\
\hline No & Yes & 5 & 5.5 & 56 & 9.3 & 0.6 & 0.2 to 1.6 & 0.30 & & \\
\hline Yes & No & 127 & 86.4 & 238 & 95.2 & 3.5 & 2.5 to 5.0 & $<0.001$ & & \\
\hline Yes & Yes & 20 & 13.6 & 12 & 4.8 & 11.0 & 4.9 to 24.3 & $<0.001$ & & \\
\hline Prenatal smoking & Breast feeding & & & & & & & & & \\
\hline No & Yes & 62 & 68.1 & 425 & 70.1 & 1.0 & Reference & - & 0.31 & 0.80 \\
\hline No & No & 29 & 31.9 & 181 & 29.9 & 1.2 & 0.7 to 2.0 & 0.45 & & \\
\hline Yes & Yes & 68 & 45.3 & 127 & 50.8 & 3.8 & 2.5 to 5.8 & $<0.001$ & & \\
\hline Yes & No & 82 & 54.7 & 123 & 49.2 & 5.1 & 3.3 to 7.9 & $<0.001$ & & \\
\hline Prenatal smoking & Infection & & & & & & & & & \\
\hline No & No & 24 & 25.8 & 312 & 51.2 & 1.0 & Reference & - & 0.17 & 0.15 \\
\hline No & Yes & 69 & 74.2 & 297 & 48.8 & 2.9 & 1.7 to 4.7 & $<0.001$ & & \\
\hline Yes & No & 49 & 32.7 & 122 & 48.2 & 5.4 & 3.1 to 9.3 & $<0.001$ & & \\
\hline Yes & Yes & 101 & 67.3 & 131 & 51.8 & 9.5 & 5.7 to 15.8 & $<0.001$ & & \\
\hline Prenatal smoking & Antibiotics & & & & & & & & & \\
\hline No & No & 70 & 75.3 & 500 & 82.9 & 1.0 & Reference & - & 0.52 & 0.13 \\
\hline No & Yes & 23 & 24.7 & 103 & 17.1 & 1.8 & 1.0 to 3.1 & 0.045 & & \\
\hline Yes & No & 112 & 75.7 & 191 & 75.8 & 4.4 & 3.1 to 6.5 & $<0.001$ & & \\
\hline Yes & Yes & 36 & 24.3 & 61 & 24.2 & 4.4 & 2.7 to 7.4 & $<0.001$ & & \\
\hline Prenatal smoking & Hospital admission & & & & & & & & & \\
\hline No & No & 62 & 66.7 & 485 & 81.0 & 1.0 & Reference & - & 0.72 & 0.097 \\
\hline No & Yes & 31 & 33.3 & 114 & 19.0 & 2.9 & 1.4 to 6.1 & 0.004 & & \\
\hline Yes & No & 107 & 71.8 & 188 & 75.8 & 4.2 & 3.0 to 6.0 & $<0.001$ & & \\
\hline Yes & Yes & 42 & 28.2 & 60 & 24.2 & 5.4 & 2.8 to 10.4 & $<0.001$ & & \\
\hline
\end{tabular}

$\mathrm{CI}=$ confidence interval; $\mathrm{OR}=$ odds ratio.

Table 6 Maternal smoking in SIDS cases and controls with crude and adjusted odds ratios (OR) by country, in Scandinavia 1992 to 1995, the Nordic epidemiological SIDS study

\begin{tabular}{|c|c|c|c|c|c|c|c|c|c|c|c|c|c|}
\hline \multirow[b]{2}{*}{ Country } & \multicolumn{2}{|c|}{ Cases } & \multicolumn{2}{|c|}{ Controls } & \multicolumn{3}{|c|}{ Crude } & \multicolumn{3}{|c|}{ Adjusted for age } & \multicolumn{3}{|c|}{$\begin{array}{l}\text { Adjusted for age, maternal age, } \\
\text { and education }\end{array}$} \\
\hline & $n$ & $\%$ & $n$ & $\%$ & $O R$ & $95 \% C I$ & $p$ & $O R$ & $95 \% C I$ & $p$ & $O R$ & $95 \% C I$ & $p$ \\
\hline \multicolumn{14}{|l|}{ Norway } \\
\hline In pregnancy & 51 & 71.8 & 93 & 34.7 & 4.1 & 2.3 to 7.3 & $<0.001$ & 4.5 & 2.3 to 8.6 & $<0.001$ & 3.9 & 2.0 to 7.9 & $<0.001$ \\
\hline After pregnancy & 49 & 69.0 & 96 & 36.2 & 4.2 & 2.3 to 7.6 & $<0.001$ & 4.6 & 2.3 to 9.2 & $<0.001$ & 4.2 & 2.0 to 8.9 & $<0.001$ \\
\hline \multicolumn{14}{|l|}{ Sweden } \\
\hline In pregnancy & 66 & 56.4 & 101 & 23.5 & 4.4 & 2.8 to 7.0 & $<0.001$ & 5.5 & 3.1 to 9.9 & $<0.001$ & 4.5 & 2.5 to 8.1 & $<0.001$ \\
\hline After pregnancy & 63 & 53.8 & 108 & 25.4 & 3.8 & 2.4 to 6.1 & $<0.001$ & 4.8 & 2.7 to 8.4 & $<0.001$ & 4.0 & 2.3 to 7.2 & $<0.001$ \\
\hline \multicolumn{14}{|l|}{ Denmark } \\
\hline In pregnancy & 33 & 60.0 & 59 & 35.8 & 3.1 & 1.5 to 6.3 & 0.002 & 3.3 & 1.5 to 7.2 & 0.004 & 1.9 & 0.8 to 4.7 & 0.17 \\
\hline After pregnancy & 34 & 61.8 & 59 & 35.1 & 3.4 & 1.7 to 6.8 & 0.001 & 4.0 & 1.7 to 9.2 & 0.001 & 2.7 & 1.1 to 7.0 & 0.034 \\
\hline
\end{tabular}

$\mathrm{CI}=$ confidence interval.

DIFFERENCES BETWEEN THE NORDIC COUNTRIES Smoking habits differed between the Scandinavian countries. In the control group Sweden had the lowest prevalence of smoking mothers during pregnancy, $23.5 \%$ against $34.7 \%$ in Norway and $35.8 \%$ in Denmark (table 6). The odds ratios for smoking were somewhat lower in Denmark and Norway, but the differences were not statistically significant (table 6). Adjusted for age of infant, maternal age, and education, the odds ratios were somewhat lower, but the pattern was the same, with the exception that the statistical significance for smoking in pregnancy disappeared in the Danish data.

The attributable fraction (AF) was $45 \%$ in the whole material. Due to the high prevalence of smoking, Norway had the highest AF (54\%), followed by Sweden (44\%) and Denmark (41\%).

\section{Discussion}

Nicotine is a powerful stimulant of cholinergic neurones, and has been postulated to act upon nicotinic acetylcholine receptors either centrally ${ }^{19}$ or peripherally. ${ }^{20}$ Given prenatally in animal experiments, it alters ventilatory and awakening responses to hypoxia. ${ }^{21-23}$ Nicotine also acts by vasoconstriction and diminution of placental blood flow, thereby reducing the amount of oxygen and nutrients available to the fetus. Prenatal smoking has been shown to have significant negative effects on neonatal airway development and lung elasticity. ${ }^{24}$ Carbon monoxide might theoretically reduce oxygen transport, and tar and smoke particles are considered responsible for an increased susceptibility to airway infections, a factor associated with SIDS. ${ }^{25}$

Our major findings were an independent effect of smoking on the risk of SIDS with a dose-response association, no effect of passive smoking, and a strong effect of smoking cessation.

It is well known that smoking reduces birth weight, and it has been argued that adjusting for birth weight carries a risk of over adjustment. ${ }^{26}$ We therefore calculated odds ratios with and without this adjustment and found slightly lower values with the adjustment, but the effects were 
still significant. This suggests an effect in addition to that mediated by the reduction in birth weight.

As in any case-control study, the result is probably affected by recall bias. Smoking might be underreported by control mothers as well as by case mothers.

To evaluate a possible non-response bias, marital status, maternal age, and birth order in the Norwegian cases and controls were compared with data from the Medical Birth Registry of Norway (MBRN) for the same period, including SIDS deaths. The proportions of single mothers, young mothers, and first births were lower in the case-control data than in the MBRN, but the reduction was similar in cases and controls.

The results from the Nordic study confirm that tobacco smoking is an independent risk factor for SIDS, and after the implementation of the supine sleeping position it has now emerged as the most important risk factor. Most infants exposed to smoking were exposed both in utero and postpartum, so the effects of prenatal and postnatal smoking are difficult to separate. ${ }^{12}{ }^{27}$ We showed that paternal smoking had no significant effect as such; it tended to augment the effect of maternal prenatal smoking, but the confidence intervals overlapped. This was also found by Blair et al. ${ }^{27}$ In our study, the mean cigarette consumption of the mother in the first trimester, when the father did not smoke, was 8.1 (7.2 to 8.9) cigarettes/ day, and when the father did smoke, 9.2 (8.4 to 9.9) cigarettes/day. The figures for the third trimester are similar: 6.3 (5.5 to 7.1$)$ and 7.9 (7.2 to 8.6) cigarettes/day, respectively. An association between maternal and paternal smoking could account for the findings in both studies.

Table 3 contains the components recently suggested by Golding ${ }^{12}$ - that is, mothers who smoked only postnatally (partial cessation) as well as mothers who smoked both prenatally and postnatally - and from this it is probable that it is maternal smoking during pregnancy that is important. We consider that paternal and other passive smoking is of relatively minor importance. This is supported by the doseresponse figures (fig 1) but we cannot rule out a small effect of maternal smoking postpartum.

The question of the influence of maternal smoking on perinatal and postnatal problems has been raised on the grounds that some children die without having been exposed to tobacco smoke, either prenatally or postnatally. In our study, $30.7 \%$ of the case mothers had never smoked. The hypothesis in this section was that it might be shown that there are differences between cases exposed and not exposed to tobacco smoke. Of the 21 variables initially investigated, only those related to feeding (poor sucking, breast feeding) and to infection (infectious symptoms, antibiotics, and hospital admission) remained.

Our interpretation of these findings is that the early feeding difficulties seen in smoke exposed cases are in some way related to the biological effects of tobacco smoke on the fetus, and that the increased risk of SIDS due to smoking is not caused by an increased risk of infections. Infection might be an additional factor that contributes to the fatal event. It is conceivable that infants who die of SIDS come from a population of infants with compromised health, and the ill effects of this are enhanced by maternal smoking.

In contrast to the findings of Haglund and Cnattingius in $1990,{ }^{28}$ we could not show a difference in age at death between the smoke exposed and non-exposed SIDS cases. We have no explanation for this.

Comparing the percentage of smoking mothers in the Scandinavian countries with the incidence of SIDS at the end of the 1980s, we note that both Norway and Denmark had very high SIDS rates, and Sweden a much lower rate. ${ }^{29}$ During the study period, Norway and Denmark both had a significantly higher proportion of smoking mothers than Sweden. These differences in smoking habits may partly reflect the varying incidences, but none of these analyses provides a convincing explanation of why Denmark and Norway differed as much as they did in the peak years 1985 to 1989 . In spite of different smoking habits, all Scandinavian countries now have virtually the same SIDS incidence. This indirectly highlights the major influence on SIDS incidence exerted by the switch to the non-prone sleeping position.

We believe we have shown a remarkable effect of maternal smoking cessation. This conveys an important message - that is, that smoking cessation is potentially beneficial. We find it curious that the infants of mothers who stopped smoking postpartum were not at increased risk, even though they had been exposed to nicotine in utero. One explanation could be that these mothers had already begun to reduce smoking during pregnancy, as was shown in the first and third trimesters. This is consistent with our demonstration of a doseresponse relation between smoking dose in pregnancy and SIDS. The fraction of mothers who changed their smoking habits was low, only 23 of 151 ; therefore the interpretation remains uncertain.

We conclude that smoking is an independent risk factor for SIDS, and that it is mainly mediated through maternal smoking during pregnancy. There are differences in smoking habits among women in Scandinavia, which are probably related to the different odds ratios observed and may have contributed to the varying incidences in the Scandinavian countries at the end of the 1980s. Analysis of smoking careers indicates that smoking cessation, or even a reduction in smoking, may be beneficial in reducing the risk of SIDS.

This study was supported by grants from the Nordic Council, the Swedish Medical Research Council, the Medical Society of Göteborg, the First of May Annual Flower Campaign, the Norwegian Research Council, the Swedish SIDS Parental Organisation, the Norwegian SIDS Parental Organisation, and the Danish SIDS Parental Organisation. We thank project coordinator P Schreuder and data consultant S Nilssen at the Medidinator Pchreuder and data consultant $S$ Nilssen at the Medical Birth Registry of Norway, $M$ Wennborg, Stockholm, and J Kjærbeck, Goteborg, for special help with data collection, and we thank the following regional coordinators: Sweden-B Ericsson, Danderyd; T Norsted, Uppsala; N Skanke, Eskilstuna; I Leijon, Linköping; A Minkova-Falk, Norrköping; NO Jonsson, Jönköping; B Larsson, Växjö; M Aldman, Västervik; I Fosdal and J Landehag, Karlskrona; B Selander, Kristianstad; T Forsberg, 
Ängelholm; N W Svenningsen, Lund; P Henriksson, Helsingborg; D Andersson, Halmstad; R Olegård and T Cederquist, L Hammaren, Bor Inganäs and U Selstam, Vänersborg-Trollhättan; K Rex, Skövde; C Lindgren, Karlstad; L Ekholm, Örebro; B Malmström, Västerås; B Eckerberg, Falun; K Hedberg, Gävle; R Sidenvall, Hudiksvall; S Mjönes, Sundsvall; I Axelsson, Ostersund; S Håkansson, Umeå; M Jurvanen, Boden; C Nilsson, Gällivare; A Lind, Kalmar; Norway - L Stoltenberg, R Lindemann, J Grøgaard, A Whitelaw, Oslo; A Ernø, Nordbyhagen; S-H Anderssen, Fredrikstad; R Palat, Elverum; H Farstad, P Christensen, Lillehammer; H Bævre, K Iversen, Giøvik; A W Søyland, K Brekke, Drammen; R Solberg, Tønsberg; S Slinde, Porsgrunn; Å Lærdal, Stavanger; G Stangeland, Kristiansand; P Scheel, Arendal; B Skadberg, Bergen; K Sydnes, Haugesund; $H$ Thomassen, Ålesund; A Alme, Volda. A-M Edsberg Kristiansund; A S Haga, Nordfjordeid; J Moldestad, berg, Kristiand Førde; S Slørdahl, Trondheim; S Børsting, Levanger; J Holt, Bodø; M Cler, Tromsø; $H$ Dramsdahl, Harstad; $H$ P cooperation with K Kock, Odense; M Gregersen, Århus.

1 Steele R, Langworth JT. The relationship of antenatal and postnatal factors to sudden unexpected death in infancy. postnatal factors to sudden unexp
Can Med Assoc $\mathcal{7} 1966 ; 94: 1165$.

2 Rintahaka PJ, Hirvonen J. The epidemiology of sudden infant death syndrome in Finland in 1969-1980. Forensic infant death syndrome in

3 Kraus JF, Greenland S, Bulterys M. Risk factors for sudden infant death syndrome in the US Collaborative Perinatal Project. Int F Epidemiol 1989;18:113-20.

4 Bulterys MG, Greenland S, Kraus JF. Chronic fetal hypoxia and sudden infant death syndrome: interaction between maternal smoking and low hematocrit during pregnancy. Pediatrics 1990;86:535-40.

5 McGlashan ND. Sudden infant deaths in Tasmania, 19801986: a seven year prospective study. Soc Sci Med 1989;29. 1015-26.

6 Mitchell EA, Scragg R, Stewart AW, et al. Results from the first year of the New Zealand cot death study. NZ Med F 1991;104:71-6.

7 Schoendorf KC, Kiely JL. Relationship of sudden infant death syndrome to maternal smoking during and after death syndrome to maternal smoking

pregnancy . Pediatrics 1992;90:905-8.
8 Mitchell EA, Stewart AW, Scragg R, et al. Ethnic differences in mortality from sudden infant death syndrome in New in mortality from sudden infant

9 Mitchell EA, Ford RP, Stewart AW, et al. Smoking and the sudden infant death syndrome. Pediatrics 1993;91:893-6.

10 Scragg R, Mitchell EA, Taylor BJ, et al. Bed sharing, smoking, and alcohol in the sudden infant death syndrome. New Zealand Cot Death Study Group. BMF 1993;307:1312-18

11 Klonoff CH, Edelstein SL, Lefkowitz ES, et al. The effect of passive smoking and tobacco exposure through breast milk on sudden infant death syndrome. $\mathcal{F} A M A$ 1995;273:795-8.

12 Golding J. Sudden infant death syndrome and parental smoking: a literature review. Paediatr Perinat Epidemiol 1997;11:67-77.
13 Gregersen M, Rajs J, Laursen H. Pathologic criteria for the Nordic Study of SIDS. In: Rognum TO, ed. Sudden infant death syndrome. New trends in the nineties. Oslo: Scandinavian University Press, 1995:50-8.

14 Øyen N, Markestad T, Skjærven R, et al. Combined effects of sleeping position and prenatal risk factors in sudden infant death syndrome: the Nordic Epidemiological SIDS Study. Pediatrics 1997;100:613-21.

15 Thompson WD. Statistical analysis of case-control studies. Epidemiol Rev 1994;16:33-50.

16 Norusis M. Advanced statistics. SPSS for Windows, release 6.0. Chicago, 1993.

17 Coughlin SS, Benichou J, Weed DL. Attributable risk estimation in case-control studies. Epidemiol Rev 1994;16: 51-64.

18 EGRET. Reference manual. 4th Revision. Seattle: Statistics and Epidemiology Research Cooperation, 1993:80-1.

19 Kinney HC, O'Donnell TJ, Kriger P, White WF. Early developmental changes in $[3 \mathrm{H}]$ nicotine binding in the developmental changes in $[3 \mathrm{H}]$ nicotine bindin

20 Holgert $H$, Hokfelt $T$, Hertzberg $T$, Lagercrantz $H$. Functional and developmental studies of the peripheral arterial chemoreceptors in rat: effects of nicotine and pos-
sible relation to sudden infant death syndrome. Proc Natl sible relation to sudden infant
Acad Sci USA 1995;92:7575-9.

21 Milerad J, Larsson H, Lin J, Sundell HW. Nicotine attenuates the ventilatory response to hypoxia in the developing lamb. Pediatr Res 1995;37:652-60.

22 Slotkin TA, Lappi SE, McCook EC, Lorber BA, Seidler FJ. Loss of neonatal hypoxia tolerance after prenatal nicotine exposure: implications for sudden infant death syndrome. Brain Res Bull 1995;38:69-75.

23 Lewis KW, Bosque EM. Deficient hypoxia awakening response in infants of smoking mothers: possible relationship to sudden infant death syndrome. 7 Pediatr 1995;127: 691-9.

24 Hanrahan JP, Tager IB, Segal MR, et al. The effect of maternal smoking during pregnancy on early infant lung function. Am Rev Respir Dis 1992;145:1129-35.

25 Lindgren C. Respiratory syncytial virus and the sudden infant death syndrome. Acta Paediatr Suppl 1993;389:67-9.

26 Weinberg CR. Toward a clearer definition of confounding. Am F Epidemiol 1993;137:1-8.

27 Blair PS, Fleming PJ, Bensley D, et al. Smoking and the sudden infant death syndrome: results from 1993-5 case-control study for confidential inquiry into stillbirths and deaths in infancy. Confidential Enquiry into Stillbirths and Deaths Regional Coordinators and Researchers. BMF 1996;313:195-8.

28 Haglund B, Cnattingius S. Cigarette smoking as a risk factor for sudden infant death syndrome: a population-based study. Am F Public Health 1990;80:29-32.

29 Milerad J, Lagercrantz H, Norvenius G, Wennergren G. Depressing development since the 1970s. The incidence of sudden infant death has doubled in all Scandinavian countries]. Läkartidningen 1992;89:1996-8. 